\title{
A escrita e a não escrita da luz
}

The writing and the non-writing of light

Roberto Gil Camargo ${ }^{1}$ 


\section{Resumo}

O objetivo deste estudo é analisar as dificuldades que há em traduzir por palavras os efeitos da luz no teatro. Partindo das diferenças conceituais entre a luz e a iluminação, o artigo propõe-se a investigar a questão da luz enquanto escrita e não escrita, tomando como exemplo o caso da chamada "luz atmosférica", em que as duas instâncias (escrita e não escrita) se fazem presentes de forma mais explícita. $O$ texto toma como referência teórica estudos de Iluminação Cênica, Arquitetura, Análise do Discurso e Análise Sociocognitiva.

Palavras-chave: Luz; iluminação; escrita; não escrita

\section{Abstract}

The aim of this study is to analyze the difficult ways of describing by words the lighting effects in theatre. Since the conceptual differences between light and lighting, the paper proposes to investigate the question of light while writing and non-writing based on the example of atmospheric light - where these two instances occur explicitly. The text takes as theoretical references some studies of Stage Lighting, Architecture, Analyze of Discourse and Sociocognitive Analysis.

ISSN: 1414.5731

E-ISSN: 2358.695

1 Prof. Dr. Universidade de Sorocaba (UNISO). Sorocaba (SP). roberto.camargo@prof.uniso.br 
No teatro, o que se escreve sobre a luz fica muito aquém do que ela realmente significa na prática. Podemos fazer longas descrições procurando os vocábulos que mais se aproximam dos efeitos visuais da luz, mas continuamos muito distantes da quantidade de impressões que experimentamos quando a luz se apresenta diante de nós, ao vivo. No entanto, para um artigo não há como descrevê-la se não por palavras!

O problema que os escritos sobre teatro enfrentam, particularmente nessa questão, é como fugir dos adjetivos e buscar uma linguagem capaz de descrever as impressões referentes à luz. Parecem mais aceitáveis aqueles que entendem a luz como um fenômeno indissociável da cena, com a qual estabelece trocas, uma explicando a outra. Nesse caso, com base na narrativa e nos meios de encenação que são utilizados, a escrita torna-se um pouco mais próxima do seu objeto de análise. Mesmo assim, as palavras ainda ficam a dever quando se trata de explicar exatamente os tipos de reações subjetivas que a luz provoca no espectador.

Luz e escrita pertencem a sistemas diferentes. A descrição que se faz da luz, por meio de palavras, além de ser uma representação simbólica do objeto em questão, parte de uma impressão individual.

A luz é um sistema aglutinante, um corpo sem órgãos, como a água e o som, que se apresentam à percepção como fenômenos contínuos, não divisíveis. $O$ que se vê da luz é exatamente aquilo que se vê naquele momento, sem tradução, sem paráfrase, num fluxo de acontecimentos simultâneos. A linguagem se esforça para traduzir em palavras a manifestação da experiência ela própria, em busca de uma isomorfia entre pensamento/representação e natureza. A questão da impossibilidade de uma linguagem verbal representar satisfatoriamente a experiência da luz parece-nos análoga ao problema da cor, exaustivamente analisado por Wittgenstein (1889-1951).

Se é quase impossível uma descrição satisfatória da luz como fenômeno capaz de impressionar os olhos e provocar reações psicológicas, não se pode dizer o mesmo da iluminação, entendida como parte técnica que trata do uso da luz para determinados fins.

Comentar a iluminação de um espetáculo com base nas evidências técnicas e procedimentos adotados torna-se possível dada a sua aproximação com a escrita. A iluminação é uma construção, uma forma de escrita também, na medida em que busca um objeto inalterável e fechado em si mesmo, pensado e criado por um autor (sujeito). Sua construção deve ser precisa, pois voltada à decifração da imagem pelos olhos do espectador.

Exatamente como acontece com a escrita de textos, a iluminação resulta de uma dispersão do sujeito: o iluminador se subjetiviza de várias maneiras à medida que vai construindo seu projeto, como se estivesse escrevendo um texto - deriva disso, provavelmente, o conceito de 'dramaturgia da luz' de que tanto se ouve falar.

Ao elaborar seu projeto, o iluminador pode pensar que está inventando algo novo, porém apenas retoma o que já existe, o que ele já viu, o que já leu e que fala dentro dele, proveniente de sua memória discursiva ("tal coisa dá certo", "isso não funciona", "convém usar menos focos", "há excesso de brilho", etc.). Há uma profusão de 'modelos mentais', para usar a expressão de Dijk (2012, p. 94-96), os quais atravessam o processo de criação com escolhas, combinações, substituições, analogias, as- 
sociações, citações, metáforas, etc. São esses percursos, procedimentos e refacções que caracterizam o trabalho de criação do iluminador.

Nas considerações escritas a respeito da iluminação no teatro, podem-se comentar a falta ou excesso de brilho, o uso abusivo de focos e cores, a ausência/presença de ritmo, os aspectos relacionados à visibilidade, dimensionalidade, seletividade e fluidez (Reid, 1976, p. 3 a 8). São detalhes técnicos e específicos do trabalho do iluminador: saber o que dizer, como dizer e com quais recursos.

Por outro lado, a preocupação maior da iluminação é com a descrição de espaço e tempo e não com a ação que ali está. A ação está na cena e não na iluminação. Há uma grande diferença entre acompanhar a ação e descrever a ação. O que acompanha a ação é a luz e não a iluminação. Daí se conclui que uma iluminação deveria dar conta das duas coisas, descrever e acompanhar, para que o espectador pudesse ver, compreender e sentir a cena.

\section{A não escrita da luz}

A luz, por si mesma, tem poder de se comunicar, devido à quantidade de estados que produz em cena, dialogando com todas as coisas e estabelecendo-se como um filtro intermediário entre o dentro (a mente do espectador) e o fora (a cena).

Mais próxima da oralidade do que da escrita, inclusive pela sua precedência histórica, a luz sempre nos surpreende, mesmo quando se trata, como no caso do teatro, de algo meticulosamente planejado pela iluminação. É exatamente a sua vitalidade que acompanha a vitalidade da cena e não os refletores da iluminação. Até mesmo quando assujeitada à iluminação, a luz é silenciosa, é subliminar, não atua no visível, mas no que está por trás dele. É a luz com sua capacidade de infiltrar-se no âmago da cena que dialoga com o sentimento, com estado de humor, com o inconsciente.

No entanto, a luz e a iluminação atuam simultaneamente no teatro, estabelecendo um jogo entre 'escrita' e 'não escrita', ora com predominância da primeira, ora da segunda, interferindo uma na outra. $O$ ponto em comum é que ambas se dirigem ao conhecimento. No entanto, sabemos que para conhecer não é preciso ler nem escrever; apenas observar, perceber e sentir.

Para esclarecer melhor a questão da luz (e não da iluminação) e as dificuldades de se descrever seus efeitos e implicações por meio de palavras, tomemos o exemplo da chamada 'luz atmosférica', que de todas as funções estéticas provavelmente seja a que mais evidencia a presença da luz enquanto algo impalpável, intangível e que ocupa um lugar intermediário entre sujeito (espectador) e objeto (cena).

Sabemos que há um componente inexprimível na luz cênica capaz de operar mudanças de estado e de humor da assistência. Algo de irracional, conforme diz Gernot Böhme² e, por conseguinte, inefável, que não se pode explicar por palavras.

A luz cênica é uma experiência compartilhada. Algo que se manifesta em conjunto, mobilizando diversos discursos e impressões subjetivas ao mesmo tempo. É uma comunicação silenciosa, aberta, sensorial, indescritível. Um dialogismo entre diversas formas de ver, perceber e sentir. O resultado dessa experiência com luz não

${ }^{2}$ Gernot Böhme, The art of the staged set as a paradigm for an aesthetics of atmospheres. http://ambiances revues.org/315. Consulta em: 2 dez. 2017. 
constitui um objeto único, estabelecido a priori com a convicção de atingir uma unanimidade, mas sim uma dispersão de subjetividades. Sabe-se lá o que se passa na mente de cada um quando assiste à cena sob a luz dos refletores. Trata-se, afinal, de uma proposição estética; como tal, pressupõe impressões e leituras heterogêneas.

A iluminação atmosférica ilustra o dialogismo que se estabelece entre cena, luz e espectador. A atmosfera é evanescente, não se fixa num ponto; ocupa o espaço de modo totalizante e expressa o tempo não como instante, mas como duração. "As atmosferas são totalidades, imbuídas de tudo: tingem o mundo, banham tudo numa só luz. Unificam uma diversidade de impressões em um único estado emotivo"3.

O efeito atmosférico banha o palco todo como se fosse uma condição circunstancial que governa a prática dialógica dos envolvidos (atores/ personagens, espectadores e o objeto de que se está tratando). É o tipo de luz constitutiva de um ambiente que influencia e transforma os participantes. Não é uma luz apenas para os olhos, mas para provocar subjetividades.

Em geral, a capacidade de a luz despertar reações subjetivas ocorre de forma invisível, sem marcas explícitas. As escolhas e combinações que perduram por mais tempo tendem a transcender os olhos do espectador e provocar nele reações mais profundas e mudanças de humor. São experiências que não atuam de forma autônoma, mas diretamente vinculadas aos acontecimentos da cena. Nesse caso, o processo cognitivo envolvido, por parte do espectador, é a percepção temporal. Sob efeito da luz, o espectador transfere a atenção do espaço para o tempo. Já as transições bruscas, muito marcadas, também podem provocar alterações, porém envolvendo como processo cognitivo predominante a percepção espacial. O impacto que a mudança brusca de luz causa na cena afeta o sistema visual, instala prontidão, curiosidade, busca, mas nem sempre vai além disso.

A luz atmosférica apresenta, como dissemos, um papel de intermediário entre sujeito e objeto. É como se houvesse alguém (o iluminador) dialogando com alguém (o espectador) sobre alguma coisa (a cena), tendo como intermediário a luz, algo imaterial que relaciona subjetividades. Para conhecê-la, o espectador precisa estar presente e acompanhar seu percurso na cena, experimentando o processo como se fizesse parte dele, contribuindo com seu próprio estado emocional. "Sem o sujeito consciente, as atmosferas não são nada"4.

Os resultados produzidos pela luz atmosférica envolvendo relações intersubjetivas constituem um estudo à parte, de natureza interdisciplinar envolvendo a estética da recepção, a análise de discurso e os estudos de sociocognição. Essas áreas do conhecimento interessam para aprofundar o estudo sobre a intangibilidade da luz como intermediária entre cena e espectador, os efeitos na percepção, o aspecto cognitivo, os modelos mentais acionados e os interdiscursos. Em suma, são referências que auxiliam na abordagem da imaterialidade da luz e seus reflexos na subjetividade.

No entanto, para a luz se materializar em cena e ao mesmo tempo dar-se a ver como algo intangível é preciso planejá-la e construí-la com os recursos técnicos aliados aos conhecimentos estéticos da iluminação.

\footnotetext{
3 Gernot Böhme, The art of the staged set as a paradigm for an aesthetics of atmospheres. http://ambiances revues.org/315. Consulta em: 2 dez. 2017.

${ }^{4}$ Gernot Böhme, The art of the staged set as a paradigm for an aesthetics of atmospheres. http://ambiances revues.org/315. Consulta em: 2 dez. 2017.
} 
Seja qual for o iluminante da cena, o efeito atmosférico não provém necessariamente do tipo de fonte, mas das interferências que a luz pode produzir nas relações entre o objeto e a percepção. Ainda que algumas fontes de luz, dadas as suas características, possam sugerir determinados estados atmosféricos, a questão principal parece estar na maneira como se lida com a luz e suas relações com o ar. A atmosfera diz respeito ao ar. Por conseguinte, o objeto dessa luz não são os corpos e as coisas, mas os intervalos que há entre eles, como se fossem pausas plenas de ar. Um ar que faz parte da cena e declara sua existência ao refletir luz. É o espaço literalmente atmosférico.

A valorização de um diálogo silencioso entre o ar e a luz transmite uma impressão particular da realidade, uma espécie de ambiente difuso onde a cena se situa. Difuso, porém não nos termos de uma luz geral de cena realista, em que o ar parece não ser levado em conta, mas do ar enquanto algo capaz de estabelecer comunicação de modo silencioso, para além do visível. O espectador tende a se habituar com o que vê, deixando-se impregnar pela evanescência de algo que passa, mas que ele não consegue ver passar, numa relação indissociável de espacialidades e temporalidades. Aos poucos, o espectador vai se apossando da experiência dramática e adotando-a para si, como se aquelas impressões fossem suas.

Transformar em palavras o que se capta de uma experiência evanescente e fugaz como a da luz, bem como descrever os efeitos que pode causar no espectador é sempre uma tarefa poética e subjetiva, muito além da evidência.

Luz e cena atuam conjuntamente e não de modo separado. Uma se dá a ver e se completa através da outra. Sem a luz, a cena não pode ser vista e sem a cena, na sua materialidade, não há reflexos nem sombras. São duas realidades que se complementam, uma exercendo influência sobre a outra. A relação entre luz e cena constitui um processo de trocas e de complementação recíproca. A luz afeta a cena, que, por sua vez, afeta a luz, produzindo um diálogo incessante, um acordo de mudanças e adaptações ininterruptas, à medida que uma se põe diante da outra. São dois processos vinculados, indissociáveis, em estado de codependência.

A interposição de fumaças e elementos translúcidos entre a luz e os corpos sobre os quais ela incide traz interferências significativas que alteram as relações que se estabelecem entre a luz e a cena. Tais condições de transmissão implicam, consequentemente, processos de readaptação da cena à luz e vice-versa, em função dos meios que se interpõem entre ambas.

Quando há fumaça no ar, a luz se depara com uma quantidade de partículas que se deslocam de forma desorganizada. Não há como controlar a inconstância dos vapores e prever os seus efeitos. A luz é obrigada a ajustar-se às condições que se apresentam. Por conseguinte, os componentes visuais da cena produzem reflexos mais fracos, pálidos e obnubilados. O brilho e a cor local das coisas se ocultam parcialmente, em virtude da fumaça, que impede o contato direto das coisas com a luz. Os resultados oscilam conforme as nuvens de fumaça se movimentam no ar. O percurso dessa viagem não é apenas visto, mas seguido, numa experiência tátil e térmica. São vários feedbacks que contribuem em silêncio para um desdobramento maior da percepção. 


\section{A escrita da luz}

A iluminação cênica tem características de escrita, na medida em que procura desenvolver uma linguagem por meio da luz e utilizar essa linguagem para diferentes fins. Nesse sentido, para iluminar um espetáculo exige-se uma série de conhecimentos ligados à criação artística e à técnica. É uma tarefa que se desenvolve por etapas, da concepção até a apresentação final, permitindo lidar com todos os recursos capazes de concretizar ideias e intenções comunicativas. Neste estudo não cabe enumerar todas as etapas que constituem a iluminação cênica, mas apenas lembrar que é uma tarefa extremamente complexa, que implica uma série de detalhes muito específicos. A energia, a matéria e a informação vêm da luz; o restante vem da capacidade de criação, do planejamento, das escolhas, das combinações e da realização disso tudo na prática.

Entendida como escrita da luz, a iluminação atua como se estivesse 'escrevendo' ou 'desenhando' com giz num quadro escuro para o espectador 'ler' o que está 'escrito'. Estamos lidando, portanto, com um processo metonímico, esse forte atrator da linguagem. A iluminação não precisa dizer tudo, mas o que é suficiente para ser visto e compreendido dentro de determinada situação cênica.

As formas escritas de comunicação têm mais autoridade e legitimidade do que as formas orais das quais derivam. Possuem regras, princípios, limites, leis, enfim, convenções. Alguns sabem escrever muito bem; outros, nem tanto e muitos ignoram completamente.

No caso da iluminação, há uma escrita que prevê como serão os resultados do ponto de vista técnico (planos de luz, design, storyboard) descrição de instrumentos, posicionamento, ângulo, direção, intensidade da luz e também resultados do ponto de vista estético, enquanto processo de criação relacionando ideia e forma, conteúdo e composição. Os dois casos implicam escolhas.

A iluminação contém uma fonte subjetiva que é responsável pelo processo de escolhas que vão desde as ideias e intenções até a seleção dos materiais, instrumentos e demais recursos de expressão. A fonte subjetiva resulta de uma diversidade de interdiscursos que trespassam o processo de criação e compõem uma assinatura, um jeito próprio de fazer. Temos aí um discurso definitivo que pode se apresentar de forma aberta a ser compartilhada com os espectadores ou de forma fechada e impositiva.

No primeiro caso, o espectador não se vê obrigado a fixar o olhar naquilo que é posto diante dele; a recepção é levada em conta como individualidade perceptiva capaz de reagir livremente à luz. No segundo, há um discurso predominante que impõe restrições à percepção, sem espaço para acionar mecanismos próprios de leitura, de acordo com a subjetividade de cada um.

O primeiro caso utiliza uma linguagem modalizada, recorrendo à seleção de ângulos, tons, intensidade, abertura, de modo a sugerir mais do que direcionar ex-

plicitamente. Não cabem mutações abruptas (sobretudo quando não motivadas); ao contrário, as transições são suaves, silenciosas ou até imperceptíveis. O discurso que está por trás do projeto propõe mais a leiturabilidade do que a simples leitura, ou 
seja, o resultado do projeto depende muito do dialogismo que a luz estabelece com a recepção.

No caso mais fechado em si, a escrita é categórica, autoritária (Gnerre, 2012), não dá margens para que o espectador 'escreva' a luz juntamente com a iluminação. A luz parece algo impresso, inalterado e fechado em si mesmo. É um processo que abstrai a presencialidade da luz, reduzida a uma escritura fixa, empacotada, seguindo regras de uso mercadológico. O discurso dominante se dá a ver pelos estereótipos, pela ostensividade e protagonismo da luz.

\section{Considerações finais}

Escrever sobre a iluminação de um espetáculo abordando seus aspectos técnicos, a sua criação estética e até mesmo as impressões gerais que pode causar no espectador é uma tarefa mais possível do que escrever sobre a luz propriamente dita e os efeitos que ela é capaz de produzir no espetáculo e no espectador.

O que os olhos veem pode ser descrito de forma objetiva, utilizando palavras de sentido denotativo ou comparações, associações e analogias. A maioria dos textos sobre iluminação cênica, inclusive as análises e resenhas críticas fazem uma abordagem que se restringe à causalidade (tal luz, tal efeito) e principalmente ao aspecto teleológico (função no espetáculo). Dificilmente essa abordagem ultrapassa os limites da percepção visual, como se a luz fosse um componente específico, mas sem identidade própria e a serviço da encenação.

Quanto à luz propriamente dita e sua capacidade de ativar a percepção e adentrar a subjetividade provocando mudanças de humor e de sentimentos, pode-se dizer que há uma indescritibilidade de algo que se dá a ver pelo invisível, pelo intangível. Isso requer uma linguagem mais interpretativa e de caráter figurado, ainda que baseada em impressões pessoais.

O efeito atmosférico da luz, citado como exemplo, "é um poder que afeta, que se apodera do assunto, como algo nebuloso que chega até nós sem se saber de onde

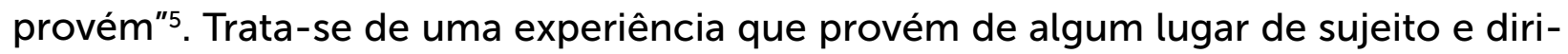
ge-se diretamente a outro sujeito, resultando, portanto, num processo de comunicação intersubjetivo.

Por fim, diferenciamos luz e iluminação, escrita e não escrita, com o objetivo de esclarecer duas instâncias que se inter-relacionam no teatro. Não se tem luz sem que haja meios para isso; não se faz nada com os meios quando não se sabe o que se pretende fazer com a luz.

\section{Referências}

BÖHME, Gernot. The art of the staged set as a paradigm for an aesthetics of atmospheres. http://ambiances revues.org/315. Consulta em: 2 dez. 2017.

\footnotetext{
${ }^{5}$ Gernot Böhme, The art of the staged set as a paradigm for an aesthetics of atmospheres. http://ambiances revues.org/315. Consulta em: 2 dez. 2017.
} 
BÖHME, Gernot. Atmospheric Architectures: The Aesthetics of Felt Spaces. New York: Bloomsbury Academic, 2017.

CAMARGO, Roberto Gill. Luz e cena: impactos e trocas. São Paulo: Revista Sala Preta (ECA-USP), vol.15, n 2, 2015.

CAMARGO, Roberto Gill. Função estética da luz. São Paulo: Perspectiva, 2012.

GNERRE, Maurizio. Linguagem, escrita e poder. São Paulo: Martins Fontes, 2012.

REID, Francis. The stage lighting handbook. New York: Theatre Arts Books, 1976.

VAN, DIJK. T.A. Discurso e contexto. São Paulo: Contexto, 2012.

Recebido em: 12/01/2018

Aprovado em: 12/01/2018 